\title{
Inspiratory muscle training in COPD: can data finally beat emotion?
}

\author{
Michael I Polkey, ${ }^{1}$ Nicolino Ambrosino ${ }^{2}$
}

Some concepts in medicine (as perhaps with other aspects of life) are so appealing that their appeal endures in the absence of data. Inspiratory muscle training (IMT) in COPD is arguably one example.

In 1976, Leith and Bradley showed, in a study undertaken in a handful of healthy subjects, ${ }^{1}$ that IMT could improve maximum inspiratory mouth pressure $\left(\mathrm{PI}_{\max }\right)$. The rationale for IMT in patients with COPD was based on the observations that $\mathrm{PI}_{\max }$ was reduced in $\mathrm{COPD}^{2}$ and on the data which seemed to show that respiratory muscle fatigue limited exercise in COPD. ${ }^{3}$ IMT was welcomed by enthusiasts perhaps because it came against a paucity of effective treatments for COPD, and early studies showed that, as with healthy volunteers, IMT could improve performance on tests of inspiratory muscle strength. As elegantly documented in a recent editorial, ${ }^{4}$ responsible opinion, including the American College of Chest Physicians, ${ }^{5}$ the American Thoracic Society and European Respiratory Society, ${ }^{6}$ continued on the one hand to recommend that IMT be included in pulmonary rehabilitation programmes (PRPs) for patients with COPD while on the other hand requesting more studies.

This story, which played over decades, in fact defied data at each stage. First, it was by no means certain that IMT improved inspiratory muscle strength; even Leith and Bradley's original work ${ }^{1}$ showed that the type of training undertaken determined which test results improved (ie, admitting an alternative hypothesis that the IMT served to improve test performance rather than true contractility). Subsequently, it was shown that IMT, despite improving performance on voluntary tests, did not increase diaphragm strength judged by phrenic nerve stimulation, ${ }^{7}$ while others showed in healthy subjects that IMT did not improve exercise performance. ${ }^{8}$

Second, in terms of the 'unmet need', the reduction in inspiratory muscle strength, which had been detected at the mouth and which IMT purported to treat, was

\footnotetext{
Department of Respiratory Medicine, Royal Brompton Hospital, London, UK

Istituti Clinici Scientifici Maugeri, IRCCS, Institute of Montescano, Pavia, Italy
}

Correspondence to Professor Michael I Polkey, Department of Respiratory Medicine, Royal Brompton Hospital, London SW3 6NP, UK; m.polkey@rbht.nhs.uk demonstrated to be due to hyperinflation rather than weakness as early as 1991 by Similowski and coworkers, ${ }^{9}$ a finding later confirmed using the technique of magnetic stimulation of the phrenic nerves. ${ }^{10}$ Similarly, the finding of diaphragm fatigue, which had been inferred from electromyographic observations, proved not to be present when the force generated by the diaphragm was evaluated in patients with COPD after hyperventilation $^{11}$ or exercise ${ }^{12}$ or even in patients on intensive care unit who failed a weaning trial. ${ }^{13}$ Such observations could indeed have been anticipated from the physiological knowledge that shortened muscle (as is the case for the diaphragm in hyperinflation) is fatigue resistant ${ }^{14}$ and subsequent studies $^{15}$ demonstrating alterations in diaphragm fibre content towards type I (fatigue resistant) fibres.

Three multicentre studies performed broadly simultaneously in recent years have now produced data, which taken together exclude a role for IMT (except within the research arena) in patients with COPD. Two were published earlier this year. In the larger Schultz and colleagues ${ }^{16}$ randomised 611 patients to receive intensive or sham IMT in the context of a 3-week inpatient rehabilitation programme. In the other Beaumont and colleagues $^{17}$ randomised 150 more severe patients to receive single blind IMT (or not) as part of a 4-week trial of rehabilitation. Charususin ${ }^{18}$ randomised 219 patients with both COPD and evidence of inspiratory muscle weakness (defined as a $\mathrm{PI}_{\max }<60$ $\mathrm{cmH}_{2} \mathrm{O}$ or $50 \%$ of predicted) to receive real or sham IMT as part of a PRP bringing to combined total of patients randomised to almost 1000 . These studies conclusively show that IMT added to PRP does not result in improved exercise performance judged by $6 \mathrm{~min}$ walk distance (6MWD), even though all three were able to increase $\mathrm{PI}_{\max }$. Conversely, it is well established that a PRP in isolation can increase 6MWD. ${ }^{19}$ Even confronted by these 'negative' studies, some authors find it difficult to discard the concept entirely and use in-depth analysis to try to obtain positive results. Thus, Schultz and colleagues note an improvement in 6MWD in women, but only by undertaking a post hoc per-protocol (as opposed to intention to treat) analysis - and even so the difference $(13 \mathrm{~m})$ did not exceed the minimal clinically important difference. ${ }^{20}$ Similarly, in the study reported here, Charususin ${ }^{18}$ observes 'Both cycling and treadmill training intensities during GET (general exercise training) sessions were slightly higher in the intervention group without reaching statistical significance $(p=0.212$ and $p=0.657$ for cycling and treadmill walking, respectively)'; this statement overlooks the purpose of statistics, which is to determine whether two numerically different numbers are actually more different than may have occurred by chance.

We suspect the popularity of IMT in COPD reflects an intrinsic human desire for a positive result and in this way leads to an alignment of beliefs of both the healthcare professional and patient; a similar alignment of beliefs underlies other popular beliefs, for example, homeopathy, and may be sufficient that such treatments are reimbursed by some governments without any scientific evidence of effectiveness. In our internet-centred (self-)medicine times, the patient's management results from input from more sources than may have been the case historically. Among these are patients' education, values and preferences, media pressures, third payer's convenience, legal fears and last (but hopefully not least...) clinical decision and competence by clinicians. Clinicians should tailor ${ }^{21}$ the best care for their individual patient on the basis of their experience, and according to the present scientific evidence it is here that, taken together, the three recent papers ${ }^{16-18}$ may be helpful in at least closing one chapter in the treatment of COPD and releasing the efforts of the patients and their carers for therapies of proven benefit.

It is of course important to recognise that a lack of benefit resulting from IMT in COPD does not preclude benefit in other scenarios. Indeed, as noted earlier, there are specific reasons why one would not expect IMT to be beneficial in COPD, not least hyperinflation. There are conditions that might benefit from short IMT programmes, such as, for example, patients with ventilator-induced diaphragm dysfunction in the recovery phase, but the lesson from COPD is that this needs to be evaluated with rigorous prospective randomised controlled trials using outcomes that are meaningful to the patient rather than simply measuring inspiratory muscle strength alone. Similarly, one could imagine that training of the expiratory muscles (EMT) could be of value in conditions where sputum retention or chest infections are a problem and where there are no biological features, such as flow limitation, likely to preclude effective training. In that context, we note that classical training modalities train both the muscle and the circuits in the brain which control them. IMT (or EMT) might 
therefore be of particular value in central neurological disease, which results in diminished lung volumes, such as stroke, ${ }^{22}$ where there is potential for plasticity.

Contributors Editorial written jointly by both of us and both agree final submission.

Funding The authors have not declared a specific grant for this research from any funding agency in the public, commercial or not-for-profit sectors.

Competing interests None declared.

Patient consent Not required.

Provenance and peer review Commissioned; internally peer reviewed.

(c) Article author(s) (or their employer(s) unless otherwise stated in the text of the article) 2018. All rights reserved. No commercial use is permitted unless otherwise expressly granted.

\section{Check for updates}

To cite Polkey MI, Ambrosino N. Thorax 2018:73:900-901.

Accepted 4 June 2018

Published Online First 26 June 2018

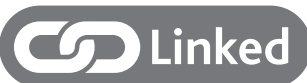

- http://dx.doi.org/10.1136/thoraxjnl-2017-211417

Thorax 2018;73:900-901.

doi:10.1136/thoraxjnl-2018-212070

\section{REFERENCES}

1 Leith DE, Bradley M. Ventilatory muscle strength and endurance training. J Appl Physiol 1976:41:508-16.

2 Byrd RB, Hyatt RE. Maximal respiratory pressures in chronic obstructive lung disease. Am Rev Respir Dis 1968;98:848-56.

3 Rochester DF, Arora NS. Respiratory muscle failure. Med Clin North Am 1983:67:573-97.

4 Ambrosino N. Inspiratory muscle training in stable COPD patients: enough is enough? Eur Respir 」 2018;51:1702285

5 Ries AL, Bauldoff GS, Carlin BW, et al. Pulmonary rehabilitation: joint ACCP/AACVPR evidence-based clinical practice guidelines. Chest 2007;131(5 Suppl):4S-42.

6 Spruit MA, Singh SJ, Garvey C, et al. An official American Thoracic Society/European Respiratory Society statement: key concepts and advances in pulmonary rehabilitation. Am I Respir Crit Care Med 2013;188:e13-e64.

7 Hart N, Sylvester K, Ward S, et al. Evaluation of an inspiratory muscle trainer in healthy humans. Respir Med 2001:95:526-31.

8 Sonetti DA, Wetter TJ, Pegelow DF, et al. Effects of respiratory muscle training versus placebo on endurance exercise performance. Respir Physiol 2001:127:185-99.

9 Similowski T, Yan S, Gauthier AP, et al. Contractile properties of the human diaphragm during chronic hyperinflation. N Engl J Med 1991:325:917-23.

10 Polkey MI, Kyroussis D, Hamnegard CH, et al. Diaphragm strength in chronic obstructive pulmonary disease. Am J Respir Crit Care Med 1996;154:1310-7.

11 Polkey MI, Kyroussis D, Hamnegard CH, et al. Diaphragm performance during maximal voluntary ventilation in chronic obstructive pulmonary disease. Am J Respir Crit Care Med 1997;155:642-8.

12 Polkey MI, Kyroussis D, Keilty SE, et al. Exhaustive treadmill exercise does not reduce twitch transdiaphragmatic pressure in patients with COPD. Am J Respir Crit Care Med 1995;152:959-64.

13 Laghi F, Cattapan SE, Jubran A, et al. Is weaning failure caused by low-frequency fatigue of the diaphragm? Am J Respir Crit Care Med 2003;167:120-7.

14 Fitch S, McComas A. Influence of human muscle length on fatigue. J Physiol 1985;362:205-13.

15 Levine S, Kaiser L, Leferovich J, et al. Cellular adaptations in the diaphragm in chronic obstructive pulmonary disease. N Engl J Med 1997:337:1799-806

16 Schultz K, Jelusic D, Wittmann M, et al. Inspiratory muscle training does not improve clinical outcomes in 3-week COPD rehabilitation: results from a randomised controlled trial. Eur Respir J 2018;51:1702000.

17 Beaumont M, Mialon P, Le Ber C, et al. Effects of inspiratory muscle training on dyspnoea in severe COPD patients during pulmonary rehabilitation: controlled randomised trial. Eur Respir I 2018;51.

18 Charususin N. A randomised controlled trial of adjunctive inspiratory muscle training for patients with COPD. Thorax. In Press.

19 Troosters T, Gosselink R, Decramer M. Short- and long-term effects of outpatient rehabilitation in patients with chronic obstructive pulmonary disease: a randomized trial. Am J Med 2000;109:207-12.

20 Polkey MI, Spruit MA, Edwards LD, et al. Sixminute-walk test in chronic obstructive pulmonary disease: minimal clinically important difference for death or hospitalization. Am J Respir Crit Care Med 2013;187:382-6.

21 Ambrosino N, Clini EM. Response to pulmonary rehabilitation: toward personalised programmes? Eur Respir J 2015:46:1538-40.

22 Ward K, Rao P, Reilly CC, et al. Poor cough flow in acute stroke patients is associated with reduced functional residual capacity and low cough inspired volume. BMJ Open Respir Res 2017:4:e000230. 